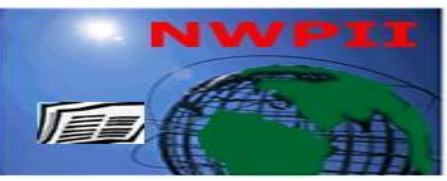

American Journal of Biomedical Sciences

ISSN: 1937-9080

nwpii.com/ajbms

\title{
Enhancement of Bone Marrow CD41+ Megakaryocytes as well as Modulation of TNF- $\alpha$, IL-12, and IL-5 by a Novel Small Molecule, UTL-5g, in Mice Treated with Cisplatin
}

\author{
Frederick Valeriote ${ }^{1}$, Ben Chen $^{2}$, Joseph Media $^{1}$, Kevin R. Bobbitt ${ }^{3}$, Jiajiu Shaw ${ }^{2^{*}}$ \\ ${ }^{1}$ Department of Internal Medicine, Henry Ford Health System, Detroit, Michigan 48202 \\ ${ }^{2} 21^{\text {st }}$ Century Therapeutics, Inc., Detroit, Michigan 48202 \\ ${ }^{3}$ Department of Public Health Sciences, Henry Ford Health System, Detroit, Michigan 48202 \\ *Corresponding author \\ Dr. Jiajiu Shaw \\ $21^{\text {st }}$ Century Therapeutics, Inc. \\ 440 Burroughs St., Suite 447 \\ Detroit, MI 48202 \\ USA \\ Tel: (7348) 330-6052 \\ E-mail: jiajiushaw@gmail.com
}

Received: 17 November 2014; | Revised: 21 December 2014; $\mid$ Accepted: 3 February 2015

\begin{abstract}
UTL-5g is a novel small-molecule chemoprotective agent against cisplatin-induced host cytotoxicity. Recent studies showed that UTL-5g increased the blood platelet count, which was reduced in cisplatintreated mice. In order to have a better understanding about the mechanism of action by which UTL-5g promotes platelet production, BDF1 mice were treated with or without UTL-5g after cisplatin treatment; several hematological analyses were conducted. The results showed that treatment of mice with UTL-5g alone by either i.p. injection or oral gavage markedly increased platelet counts. UTL-5g also restored bone marrow cell counts that were reduced by cisplatin treatment. Flow cytometric analysis showed that bone marrow CD41+ megakaryocytic cells were significantly increased in animals pretreated with UTL-5g before cisplatin. Measurement of secreted cytokines showed that pretreatment of UTL-5g lowered blood levels of both TNF- $\alpha$ and IL-12 (p70) elevated by cisplatin treatment. On the other hand, pretreatment of UTL-5g raised blood levels of IL-5 that were lowered by cisplatin treatment. The results also showed that $60 \mathrm{mg} / \mathrm{kg}$ is the optimal dose of UTL-5g by oral route for the protection of bone marrow cells, CD41+ megakaryocytes, and platelets. In conclusion, this study suggests that UTL-5g (by i.p. injection or oral gavage) enhances the production of platelets by either protecting or increasing bone marrow CD41+ megakaryocytic cells at least in part; UTL-5g also modulates TNF- $\alpha$, IL-12 (p70), and IL-5. Taken together, these observed effects of UTL-5g on megakaryocytes and cytokines play important roles in the chemoprotective properties of UTL$5 \mathrm{~g}$.
\end{abstract}

Keywords: chemoprotective agent, cisplatin, platelets, CD41+ megakaryocytes, bone marrow cells. 


\section{Introduction}

Cisplatin is a widely used cytotoxic agent with activity against many human cancers including testicular, ovarian, gastrointestinal, head and neck, and lung. However, cisplatin is also associated with substantial undesirable side effects, a major one being nephrotoxicity, which evolves slowly but predictably after initial and repeated exposure [1, 2]. Another side effect associated with cisplatin is hepatotoxicity, which is the dose-limiting toxicity. Hepatotoxicity occurs when cisplatin is administered at high doses $[3,4]$ and is often associated with the elevation of alanine aminotransferase (ALT), aspartate aminotransferase (AST), nitric oxide (NO) and calcium levels in the blood [5]. Additionally, about 25 to 30 percent of patients undergoing cisplatin treatment may also develop myelosuppression [6], in which the numbers of platelets and white blood cells (leukocytes) are severely reduced following 2 to 3 weeks of treatment. The loss of platelets (thrombocytopenia) and leukocytes (leukopenia) are more pronounced when higher doses of cisplatin are given [6].

To overcome these toxic side effects, many natural and synthetic compounds have been investigated and shown to be chemoprotective $[7,8]$. Yet, there is only one FDA approved drug being widely used as a broad-spectrum chemoprotector, amifostine, which is a sulfurcontaining agent that reduces side effects from various chemotherapy and radiotherapy regimens $[9,10]$. Unfortunately, amifostine is also associated with a number of side effects [10]. In addition, amifostine may hamper the therapeutic effect by rapid chemical quenching of cisplatin to form an inactive platinum-thiol conjugate species [11]. Therefore, the search for a significantly improved chemoprotective agent against cisplatin-induced side effects continues.

Among the earliest molecular effects caused by cisplatin are the activation of the mitogenactivated protein kinase (MAPK) signaling cascade and molecular pathway responses to stress. Inflammatory cascades are important determinants of the degree of organ failure induced by cisplatin, which are often associated with abnormal induction of TNF- $\alpha$ in both affected tissues and blood. Recent studies showed that TNF- $\alpha$ plays a crucial role in the pathogenesis of cisplatin-induced nephrotoxicity [12-15]. Zhang et al. showed that the production of TNF- $\alpha$ by renal parenchymal cells is responsible for cisplatin-induced nephrotoxicity [16]. Still others showed that chemoprotection by phenolic antioxidants is through the control of TNF- $\alpha$ induction, indicating that modulation of TNF- $\alpha$ is a potential mechanism to achieve chemoprotection [17]. Excessive amounts of TNF- $\alpha$ have also been shown to cause severe injury and damage to normal tissues and bone marrow hematopoietic stem cells resulting in thrombocytopenia and leucopenia $[18,19]$.

We have shown that a small-molecule, UTL-5g, lowered TNF- $\alpha$ levels elevated by cisplatin and reduced cisplatin-induced hepatotoxicity and nephrotoxicity [20]. We also showed that UTL-5g could reduce the acute liver damage caused by local irradiation [21]. In addition, we showed that UTL-5g can markedly increase blood platelet counts in cisplatin-treated mice [20] indicating that UTL-5g might be effective in suppressing cisplatin-induced thrombocytopenia. Therefore, UTL-5g is a potential chemoprotective agent worth further investigation; this work was set up to gain a better understanding about the potential mechanism of action by which UTL-5g protects platelet production.

Platelet glycoprotein IIb (CD41 antigen) is expressed on mature platelets and megakaryocytes as well as their progenitor cells in bone marrow [22-24]. CD41 associates with CD61 (platelet glycoprotein IIIa) in a complex to form the integrin GPIIb/IIIa, which plays a major role in platelet function [25]. Since CD41 is thought to be highly specific to cells in the megakaryocytic/platelet lineage, we set out to investigate the effect of UTL-5g on the number of CD41 cells in mouse bone marrow following cisplatin and with and without UTL-5g pretreatments. We now report that the increase of blood platelet counts by UTL-5g may be through either protecting or enhancing the number of 
bone marrow $\mathrm{CD} 41+$ cells in mouse at least in part.

\section{Materials and Methods}

\subsection{Chemicals reagents and media}

UTL-5g (Lot \#1182-MEM-3D, Purity >99\%) was synthesized by Kalexsyn (Kalamazoo, MI). Alpha-MEM was purchased from MediaTech (Manassas, VA). Bovine calf serum was purchased from HyClone Laboratories (Logan, Utah, US). Bio-Plex Pro ${ }^{\mathrm{TM}}$ Mouse Cytokine Th1/Th2 assay for IL-2, IL-4, IL-5, IL-10, IL-12 (p70), GM-CSF, IFN- $\gamma$, and TNF- $\alpha$ (M6000003J7) and Bio-Plex Pro ${ }^{\mathrm{TM}}$ TGF- $\beta$ 3-plex assay for TGF- $\beta 1,2$ and $3(171-W 4001 \mathrm{M})$ were purchased from BioRad (Hercules, CA). Allophycocyanin conjugated anti-murine CD41 antibody (APC-anti-CD41) was obtained from BioLegend (San Diego, CA). All other chemicals were purchased from Sigma-Aldrich (St. Louis, MO) unless otherwise specified.

\subsection{Animals}

BDF1 female mice (8-10 weeks, 20 g each) were purchased from Charles River (Wilmington, MA). All animal studies were in full compliance with the Institutional Animal Care and Use Committee (IACUC) guidelines.

\subsection{Preparation of UTL-5g and cisplatin}

For i.p. injection $(60 \mathrm{mg} / \mathrm{kg})$, UTL- $5 \mathrm{~g}$ was dissolved in equal volume of dimethyl sulfoxide (DMSO) and cremophor/propylene glycol (60/40 $\mathrm{v} / \mathrm{v})$. The solution was then diluted with saline $(1: 9 \mathrm{v} / \mathrm{v})$ to the final concentration $4.8 \mathrm{mg} / \mathrm{mL}$. For oral gavage $(60,120$ and $240 \mathrm{mg} / \mathrm{kg})$, UTL$5 \mathrm{~g}$ was dispersed in OraPlus® (Paddock Laboratories), by using a mortar and pestle to make suspensions of UTL-5g at 4.8, 9.6, and 19.2 $\mathrm{mg} / \mathrm{mL}$, respectively. Cisplatin was dissolved directly in saline to $0.2 \mathrm{mg} / \mathrm{mL}$.

\subsection{Animal Studies}

BDF1 female mice were randomly divided into six groups (5 mice per group) and each treated as follows: (Group A) medium (saline) followed by medium (saline) $30 \mathrm{~min}$ later; (Group B) medium (saline) followed by cisplatin
(2.5 mg/kg, i.v.) $30 \mathrm{~min}$ later; (Group C) UTL$5 \mathrm{~g}(60 \mathrm{mg} / \mathrm{kg}$, i.p. $)$ followed by cisplatin $(2.5$ $\mathrm{mg} / \mathrm{kg}$, i.v.) $30 \mathrm{~min}$ later; (Group D) UTL-5g (60 $\mathrm{mg} / \mathrm{kg}$, oral) followed by cisplatin $(2.5 \mathrm{mg} / \mathrm{kg}$, i.v.) $30 \mathrm{~min}$ later; (Group E) UTL-5g (120 mg/kg, oral) followed by cisplatin $(2.5 \mathrm{mg} / \mathrm{kg}, i . v)$. min later and (Group F) UTL-5g (240 mg/kg, oral) followed by cisplatin $(2.5 \mathrm{mg} / \mathrm{kg}, i . v$. $) 30$ min later. UTL-5g administration volume (either i.p. injection or oral gavage) was $0.25 \mathrm{~mL} / \mathrm{mouse}$ daily for 5 days. Cisplatin was prepared as a single injection. On day 6, blood from each animal was obtained by cardiac puncture in a heparinized syringe. White blood cells and platelet counts from each blood sample were carried out using a Leukochek ${ }^{\mathrm{TM}}$ test kit (Biomedical Polymers, Gardner, MA) diluting systems and a hemocytometer. Bone marrow cell count was performed for each animal and bone marrow cells were processed for CD41+ megakaryocytes (Mk) as described below.

\subsection{Preparation for CD41+ megakaryocytes and cytokine analysis}

Bone marrow cells $\left(1 \times 10^{6}\right.$ cells $)$ were fixed in $4 \%$ paraformaldehyde diluted with staining buffer ( 1 x PBS, $0.1 \%$ sodium azide, $0.5 \%$ BSA). After fixing, cells were washed once in staining buffer then incubated with anti-murine CD41 antibody conjugated with allophycocyanin (APC) (BioLegend, San Diego, CA). After incubation at room temperature for $30 \mathrm{~min}$, cells were washed with staining buffer followed by PBS. Thereafter, cells were fixed with $3 \mathrm{~mL}$ of ice cold ethanol added dropwise while vortexing. All samples were then incubated overnight at $4{ }^{\circ} \mathrm{C}$ in the dark. On the following day, cells were pelleted, ethanol was aspirated, and pellets washed once with PBS. After washing, cells were incubated for $2 \mathrm{hr}$ at 4 ${ }^{\circ} \mathrm{C}$ with propidium iodide (PI) staining solution (eBioscience, San Diego, CA) to stain DNA then 100,000 PI+ events for analysis were acquired using an LSRII flow cytometer (BD Biosciences, San Jose, CA) and results were analyzed using DIVA software (v 6.1.3).

The levels of blood cytokines were analyzed using Bio-Plex Pro ${ }^{\text {TM }}$ Th12/Th2 mouse cytokine assay (BioRad) according to the manufacturer's instruction. Plasma samples $(50 \mu \mathrm{L}$ of sample 
dilution/well) from each group were analyzed using the Bio-plex 200 (BioRad) for both TNF- $\alpha$ and interleukin-5 (IL-5). Samples for TGF- $\alpha$ (1, 2 and 3) determination were measured separately using the Bio-Plex Pro ${ }^{\text {TM }}$ TGF- $\beta$ 3-plex assay, following the manufacturer's directions(BioRad). Cytokine concentrations were determined using Bio-plex Manager Software (v 5.0) (BioRad).

\section{Results and Discussion}

\subsection{Effect of UTL-5g on platelet count}

As shown in Fig. 1, the pretreatment of UTL$5 \mathrm{~g}$ by either i.p. injection or oral gavage significantly increased the platelet counts as compared to animals treated with cisplatin only (group B). Both groups C $(60 \mathrm{mg} / \mathrm{kg}$, i.p. injection) and $\mathrm{D}(60 \mathrm{mg} / \mathrm{kg}$ oral gavage) showed significant increases of platelet counts $(28 \%$ and $30 \%$ respectively). Groups E $(120 \mathrm{mg} / \mathrm{kg}$, oral gavage) and $\mathrm{F}$ (240 mg/kg, oral gavage) also showed a statistically significant increase in the platelet counts as compared to Group B (34\% and $46 \%$ respectively). This observation is consistent with what we reported in the previous studies where we showed that the pretreatment of UTL$5 \mathrm{~g}$ increased platelet counts whether the animals were treated with cisplatin (30 min later) or not [20]. These results also showed that the optimal oral dose for UTL-5g under current experimental conditions appears to be in the range of 60 to 120 $\mathrm{mg} / \mathrm{kg}$.

\subsection{Effect of UTL-5g on bone marrow cells}

The regimen used for cisplatin treatment (2.5 $\mathrm{mg} / \mathrm{kg} \times 5$ ) was sufficient to cause significant bone marrow injury. As shown in Table 1, animals treated with cisplatin (Group B) have much lower bone marrow cell counts as compared to those in the control group (Group A) $\left(6.84\right.$ vs. $\left.12.1 \times 10^{6}\right)$. In animals pretreated with UTL-5g (whether by i.p. or oral administration), the reduced bone marrow cell counts were partially recovered, indicating that UTL-5g protected overall bone marrow cells from cisplatin-induced injury. The protection by UTL$5 \mathrm{~g}$ was significantly increased with i.p. $60 \mathrm{mg} / \mathrm{kg}$ (Group C) $\left(8.83 \times 10^{6}\right)$ and oral $60 \mathrm{mg}$ or 120 $\mathrm{mg} / \mathrm{kg} \quad\left(9.66\right.$ and $9.32 \times 10^{6}$ respectively $)$ compared to Group B $\left(6.84 \times 10^{6}\right)$ wherein animals were treated with cisplatin only. However, at $240 \mathrm{mg} / \mathrm{kg}$ of UTL-5g (Group F), the recovery of bone marrow cells was slightly less than those treated with lower doses of UTL$5 \mathrm{~g}$ indicating that UTL-5g at $240 \mathrm{mg} / \mathrm{kg}$ is above the optimal dose. In addition, our results indicate that, under current experimental conditions, the hematological effects of UTL-5g by oral administration at $60 \mathrm{mg} / \mathrm{kg}$, is similar to that by i.p. injection and the optimal oral dose is around $60 \mathrm{mg} / \mathrm{kg}$ with respect to bone marrow protection.

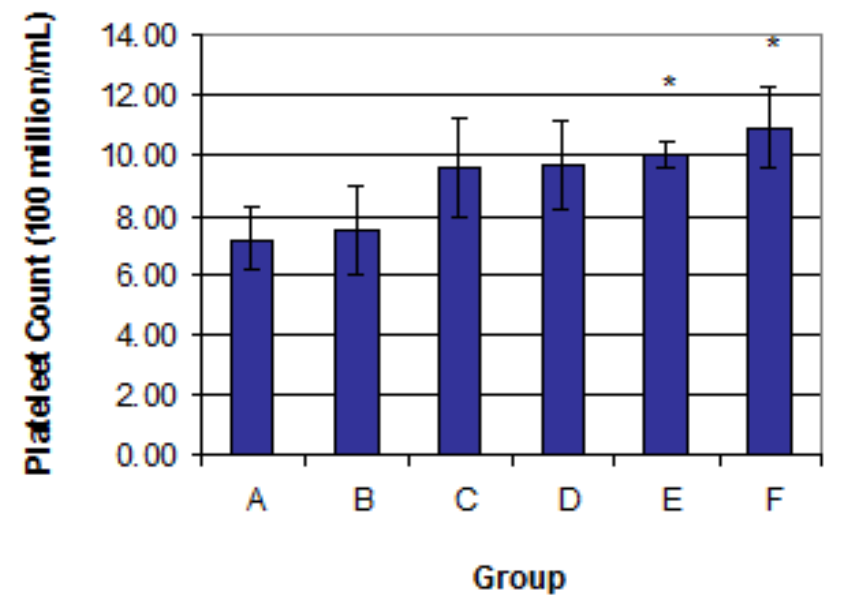

Figure 1. Comparing the effect of UTL-5g pretreatment on platelet count by i.p. injection and by oral gavage.

(Group A) Control (saline); (Group B) cisplatin (2.5 $\mathrm{mg} / \mathrm{kg})$; (Group C) UTL-5g (60 mg/kg, i.p.) followed by cisplatin $(2.5 \mathrm{mg} / \mathrm{kg})$; (Group D) UTL-5g (60 $\mathrm{mg} / \mathrm{kg}$, oral) followed by cisplatin $(2.5 \mathrm{mg} / \mathrm{kg}$ ); (Group E) UTL-5g (120 mg/kg, oral) followed by cisplatin (2.5 mg/kg); (Group F) UTL-5g (240 $\mathrm{mg} / \mathrm{kg}$, oral) followed by cisplatin $(2.5 \mathrm{mg} / \mathrm{kg})$. * $\mathrm{P}<0.05$ for Group B vs Group E and Group B vs Group F.

\subsection{Effect of UTL-5g on bone marrow CD41+ cells}

In an attempt to better understand how the platelet count is increased by UTL-5g, CD41 expression on MKs was performed using flow cytometry. . Bone marrow c were obtained from mice treated with different doses of UTL- $5 \mathrm{~g}$ were analyzed for CD41 expression. Intact cells were 
first gated using forward and side scatter properties (Fig. 2A). These cells were subsequently gated using PI staining (Fig. 2B), and PI+ cells were then analyzed for CD41 expression (Fig. 2C). We observed higher levels of CD41 positive cells from animals pretreated with i.p. UTL-5g at $60 \mathrm{mg} / \mathrm{kg}(1.36 \%)$ and oral UTL-5g at 60 and $120 \mathrm{mg} / \mathrm{kg}(1.82$ and $1.70 \%$ respectively) than did cells from untreated animals $(1.08 \%)$ or those treated with cisplatin alone (1.28\%); oral UTL-5g at $240 \mathrm{mg} / \mathrm{kg}$ appeared to be sub-optimal (Table 1). When normalized for bone marrow cellularity, it became clear that the levels of CD41+ megakaryocytes were significantly higher for all groups pretreated with UTL-5g, whether by oral or i.p. administration. Furthermore, under current experimental conditions, using the daily $\mathrm{x} 5$ schedule, oral administration of UTL-5g at 60 or $120 \mathrm{mg} / \mathrm{kg}$ appears to be optimal doses for increasing levels of CD41+ megakaryocytes. This dose-bioactivity relationship is similar to that observed in bone marrow protection by UTL-5g (Table 1).

(A)

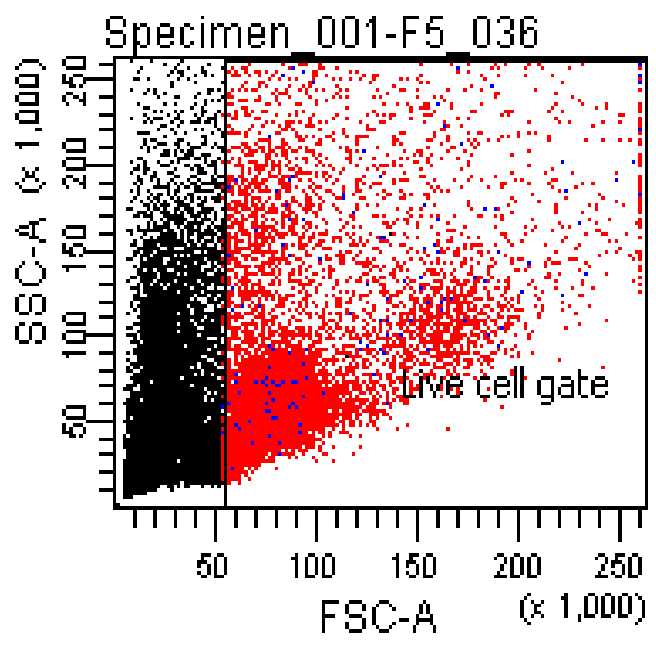

(B)

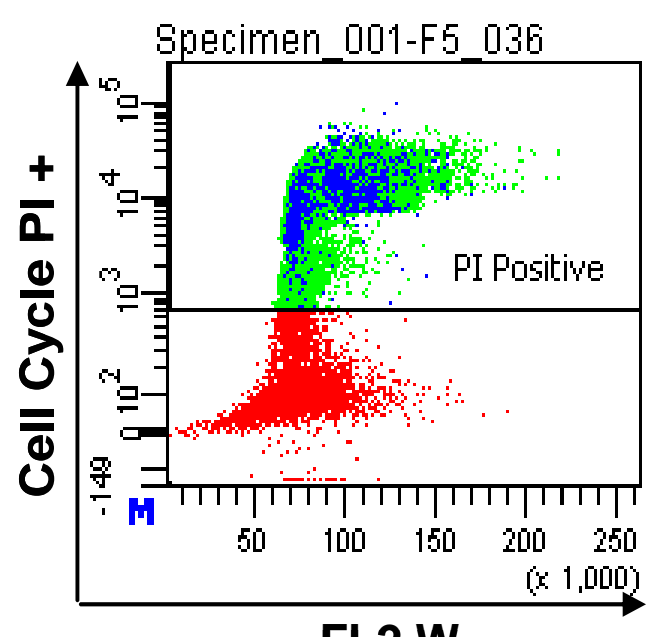

FL2 W

(C)

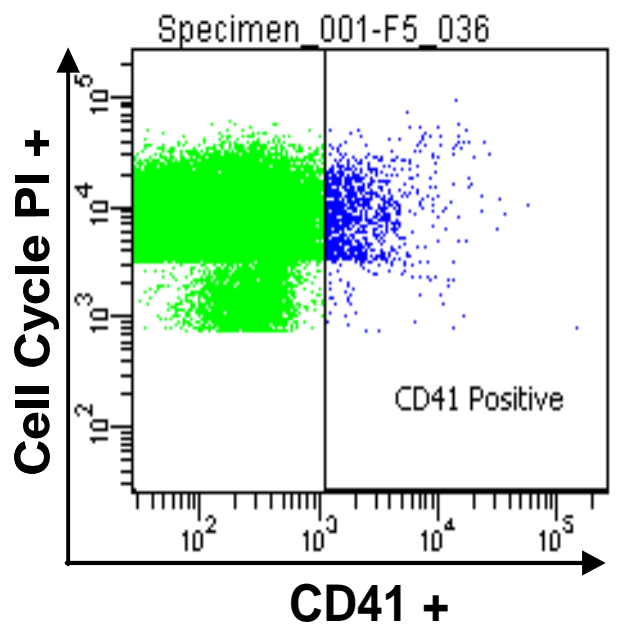

Figure 2. Gating strategy for CD41 expression on megakaryocytes.

(A) Intact cells were gated to exclude debris and dead cells. (B) These cells were subsequently gated using PI staining. (C) PI+ cells were analyzed for CD41 expression. 
Table 1. CD41 Expressing Megakaryocytic Cells Normalized for Bone Marrow Cellularity ${ }^{\mathrm{a}}$

\begin{tabular}{|c|c|c|c|c|c|c|}
\hline Group & A & B & $\mathrm{C}$ & $\mathrm{D}$ & $\mathrm{E}$ & $\mathrm{F}$ \\
\hline & Control & Cisplatin & $\begin{array}{l}\text { UTL-5g } 60 \\
\text { mg/kg i.p. + } \\
\text { cisplatin } \\
\end{array}$ & $\begin{array}{l}\mathrm{UTL}-5 \mathrm{~g} 60 \\
\mathrm{mg} / \mathrm{kg} \text { oral }+ \\
\text { cisplatin } \\
\end{array}$ & $\begin{array}{l}\text { UTL-5g } 120 \\
\mathrm{mg} / \mathrm{kg} \text { oral. }+ \\
\text { cisplatin } \\
\end{array}$ & $\begin{array}{l}\text { UTL-5g } 240 \\
\text { mg/kg oral + } \\
\text { cisplatin } \\
\end{array}$ \\
\hline Bone marrow cell count $\left(10^{6}\right)$ & $12.1 \pm 1.13$ & $6.84 \pm 0.43$ & $8.83 \pm 0.60$ & $9.66 \pm 0.40$ & $9.32 \pm 1.16$ & $7.59 \pm 0.39$ \\
\hline $\begin{array}{l}\text { \%CD41+ Mk in Cell Cycle PI+ } \\
\text { gate }\end{array}$ & 1.08 & 1.28 & 1.36 & 1.82 & 1.70 & 1.34 \\
\hline $\begin{array}{l}\text { CD41+ Mk normalized for bone } \\
\text { marrow cellularity }\left(10^{4}\right)\end{array}$ & $13.1 \pm 1.22$ & $8.75 \pm 0.55$ & $12.0 \pm 0.82$ & $17.6 \pm 0.73$ & $15.8 \pm 1.97$ & $10.2 \pm 0.52$ \\
\hline $\begin{array}{l}\text { Ratio of CD41+ Mk as } \\
\text { compared to Group A }\end{array}$ & 1 & 0.67 & 0.92 & 1.34 & 1.21 & 0.78 \\
\hline
\end{tabular}

\footnotetext{
${ }^{\mathrm{a}}$ Each number represents average \pm standard error of 4 mice (groups $\mathrm{A}, \mathrm{D}$, and E) and 5 mice (groups B, C, F).
}

\subsection{Effects of UTL-5g on blood levels of TNF - $\alpha, I L-12$ (p70), and IL-5}

Cytokine assay results (Table 2) show that blood levels of both TNF- $\alpha$ and IL-12 (p70) were significantly elevated by cisplatin while that of IL-5 was significantly lowered by cisplatin (group B) as compared with control (group A). TNF- $\alpha$ was increased by $58 \%$, IL-12 (p70) was increased by $257 \%$, and IL-5 was decreased by $42 \%$. For groups D and E, mice were pretreated with oral UTL-5g at 60 and $120 \mathrm{mg} / \mathrm{kg}$, elevated TNF- $\alpha$ blood levels were significantly lowered, which is consistent with our previous observations [20]. It is not clear why the other doses, i.p. $60 \mathrm{mg} / \mathrm{kg}$ and oral $240 \mathrm{mg} / \mathrm{kg}$ (groups $\mathrm{C}$ and F) slightly increased TNF- $\alpha$ levels.

Table 2. Effect of UTL-5g on Blood Levels of Cytokines

\begin{tabular}{|c|c|c|c|c|c|c|}
\hline Group $^{\mathrm{a}}$ & $\mathrm{A}$ & $\mathrm{B}$ & $\mathrm{C}$ & $\mathrm{D}$ & $\mathrm{E}$ \\
\hline & Control & Cisplatin & $\begin{array}{c}\text { UTL-5g } 60 \\
\mathrm{mg} / \mathrm{kg} \text { i.p. }+ \\
\text { cisplatin }\end{array}$ & $\begin{array}{c}\text { UTL-5g 60 } \\
\text { mg/kg oral }+ \\
\text { cisplatin }\end{array}$ & $\begin{array}{c}\text { UTL-5g 120 } \\
\mathrm{mg} / \mathrm{kg} \text { oral. }+ \\
\text { cisplatin }\end{array}$ & $\begin{array}{c}\text { UTL-5g 240 } \\
\mathrm{mg} / \mathrm{kg} \text { oral }+ \\
\text { cisplatin }\end{array}$ \\
\hline TNF- $\alpha(\mathrm{pg} / \mathrm{mL})$ & $193 \pm 33.5$ & $306 \pm 31.1$ & $346 \pm 53.8$ & $186 \pm 11.1$ & $269 \pm 42.3$ & $366 \pm 23.6$ \\
\hline IL-12 $(\mathrm{p} 70)(\mathrm{pg} / \mathrm{mL})$ & $8.9 \pm 6.6$ & $31.8 \pm 2.6$ & $13.9 \pm 5.0$ & $14.9 \pm 0.9$ & $23.0 \pm 7.4$ & $29.2 \pm 4.4$ \\
\hline IL-5 $(\mathrm{pg} / \mathrm{mL})$ & $21.9 \pm 5.4$ & $12.8 \pm 1.6$ & $74.0 \pm 50.0$ & $170 \pm 159$ & $16.4 \pm 4.5$ & $85.7 \pm 45.8$ \\
\hline
\end{tabular}

${ }^{\mathrm{a}}$ Each number represents average \pm standard error of 5 mice (groups B) and 5 mice (all other groups).

IL-12 is a biomarker of the disease activity in polyneuropathy, organomegaly, endocrinopathy, M-protein, and skin changes syndrome (POEMS). The overproduction of IL-12 could contribute to the peripheral nerve demyelination characteristic in POEMS [26]. Elevated levels of IL-12 (p70) is associated with optic neuropathy in human primary open angle glaucoma [27]. Table 2 shows that UTL-5g significantly lowered elevated levels of IL-12 (p70) in blood, whether it was administered orally or by i.p. injection; UTL$5 \mathrm{~g}$ at $60 \mathrm{mg} / \mathrm{kg}$ (either by i.p. or oral administration) appeared to be the optimal dose for lowering IL-12 (p70). These results indicate that UTL-5g may also be a potential agent for treating neuropathy related disorders.

IL-5 is an important cytokine that regulates B cell growth, immunoglobulin secretion, eosinophil activation and survival [28]. Levels of IL-5 were markedly lowered $(58 \%)$ by cisplatin treatment, indicating that cisplatin may contribute to some negative biological and immunological side effects; the immunosuppressive effect of cisplatin has been reported in previous studies 
$[29,30]$. Our finding suggests that reduction of IL-5 may contribute, in part to the immunotoxic effect of cisplatin. As shown in Table 2, the lowering of IL-5 levels by cisplatin was reversed by UTL-5g whether it was administered orally or by i.p. injection.

Overall, oral UTL-5g at $60 \mathrm{mg} / \mathrm{kg}$ appeared to be the optimal dose in lowering blood levels of TNF- $\alpha /$ IL-12 (p70) and in elevating IL-5. No significant changes were observed in this study for other cytokines tested, including TGF- $\beta(1,2$, and 3), GM-CSF, IL-2, IL-4, and IFN- $\gamma$.

In summary, this study suggests that UTL-5g (by i.p. injection or oral gavage) enhances the production of platelets, at least in part, by either protecting or increasing bone marrow CD41+ megakaryocytic cells adversely affected by cisplatin; UTL-5g also modulates blood levels of TNF- $\alpha$, IL-12 (p70), and IL-5 abnormally regulated by cisplatin. Taken together, these observed beneficial effects of UTL-5g on megakaryocytes and cytokines play important roles in the chemoprotective properties of UTL$5 \mathrm{~g}$.

\section{Acknowledgement}

This work was supported by SBIR grant 2R44CA141749-02 from the National Cancer Institute, National Institutes of Health, Department of Health and Human Services, USA.

Abbreviation: APC, allophycocyanin; BSA, bovine serum albumin; IL-5, interleukin-5; IL-12, interleukin-12; Mk, megakaryocytes; PBS, phosphate-buffer saline; PI, propidium iodide; TGF- $\beta$, transforming growth factor-beta; TNF- $\alpha$, tumor necrosis factor-alpha.

\section{References}

1. Reed E. Cisplatin and its analogs. In: DeVita VT, Lawrence TS, Rosenberg SA, editors. DeVita, Hellman, and Rosenberg's Cancer: Principles \& Practice of Oncology Philadelphia, Pa: Lippincott Williams \& Wilkins; 2008. p p.419.
2. Madias NE, Harrington JT. Platinum nephrotoxicity. Am J Med 1978;65:307-314. PMID: 99034

3. Cavalli F, Tschopp L, Sonntag RW, et al. A case of liver toxicity following cisdichlorodiammineplatinum(II) treatment. Cancer Treat Rep 1978;62:2125-2126. PMID: 751721

4. Cersosimo RJ. Hepatotoxicity associated with cisplatin chemotherapy. Ann Pharmacother 1993;27:438-441. PMID: 8477119

5. Mansour HH, Hafez HF, Fahmy NM. Silymarin modulates Cisplatin-induced oxidative stress and hepatotoxicity in rats. $\mathbf{J}$ Biochem Mol Biol 2006;39:656-661. PMID: 17129399

6. Gill I, Muggia FM, Terheggen PM, et al. Dose-escalation study of carboplatin (day 1) and cisplatin (day 3 ): tolerance and relation to leukocyte and buccal cell platinum--DNA adducts. Ann Oncol 1991;2:115-121. PMID: $\underline{2054312}$

7. Subbiah U, Raghunathan M. Chemoprotective action of resveratrol and genistein from apoptosis induced in human peripheral blood lymphocytes. J Biomol Struct Dyn 2008;25:425-434. PMID: 18092837

8. Psotova J, Chlopcikova S, Miketova P, et al. Chemoprotective effect of plant phenolics against anthracycline-induced toxicity on rat cardiomyocytes. Part III. Apigenin, baicalelin, kaempherol, luteolin and quercetin. Phytother Res 2004;18:516-521. DOI: $10.1002 /$ ptr. 1462

9. Culy CR, Spencer CM. Amifostine: an update on its clinical status as a cytoprotectant in patients with cancer receiving chemotherapy or radiotherapy and its potential therapeutic application in myelodysplastic syndrome. Drugs 2001;61:641-684. PMID: 11368288

10. Mabro M, Faivre S, Raymond E. A riskbenefit assessment of amifostine in cytoprotection. Drug Saf 1999;21:367-387. PMID: 10554052

11. Hausheer FH, Kanter $\mathrm{P}$, Cao $\mathrm{S}$, et al. Modulation of platinum-induced toxicities and therapeutic index: mechanistic insights and first- and second-generation protecting 
agents. Semin Oncol 1998;25:584-599. PMID: 9783598

12. Ramesh G, Reeves WB. Salicylate reduces cisplatin nephrotoxicity by inhibition of tumor necrosis factor-alpha. Kidney Int 2004;65:490-499. PMID: 14717919

13. Ramesh G, Reeves WB. TNF-alpha mediates chemokine and cytokine expression and renal injury in cisplatin nephrotoxicity. J Clin Invest 2002;110:835-842. PMID: 12235115

14. Ramesh G, Reeves WB. p38 MAP kinase inhibition ameliorates cisplatin nephrotoxicity in mice. Am $\mathbf{J}$ Physiol Renal Physiol 2005;289:F166-174. PMID: 15701814

15. Tsuruya K, Ninomiya T, Tokumoto M, et al. Direct involvement of the receptor-mediated apoptotic pathways in cisplatin-induced renal tubular cell death. Kidney Int 2003;63:72-82. PMID: 12472770

16. Zhang B, Ramesh G, Norbury CC, et al. Cisplatin-induced nephrotoxicity is mediated by tumor necrosis factor-alpha produced by renal parenchymal cells. Kidney Int 2007;72:37-44. PMID: 17396112

17. Ma Q, Kinneer K. Chemoprotection by phenolic antioxidants. Inhibition of tumor necrosis factor alpha induction in macrophages. J Biol Chem 2002;277:24772484. PMID: 11694529

18. Kerzic PJ, Pyatt DW, Zheng JH, et al. Inhibition of NF- $\mathrm{BB}$ by hydroquinone sensitizes human bone marrow progenitor cells to TNF- $\alpha$-induced apoptosis. Toxicology 2003; 187:127-137. PMID: 12699902

19. Mundle SD, Ali A, Cartlidge JD, et al. Evidence for involvement of tumor necrosis factor- $\alpha$ in apoptotic death of bone marrow cells in myelodysplastic syndromes. Am J Hematol 1999;60:36-47. PMID: 9883804

20. Shaw J, Chen B, Huang WH, et al. The smallmolecule TNF-alpha modulator, UTL-5g, reduces side effects induced by cisplatin and enhances the therapeutic effect of cisplatin in vivo. J Exp Ther Oncol 2011;9:129-137. PMID: 21699020

21. Shaw J, Zhang J, Zhang $M$, et al. Pretreatment with A Small-Molecule Tumor
Necrosis Factor-Alpha (TNF- $\alpha$ ) Inhibitor, UTL-5g, Reduced Radiation-Induced Acute Liver Toxicity in Mice. Am J Biomed Sci 2012;4:123-131. doi: 10.5099/aj120200123

22. Mitjavila-Garcia MT, Cailleret M, Godin I, et al. Expression of CD41 on hematopoietic progenitors derived from embryonic hematopoietic cells. Development 2002;129:2003-2013. PMID: 11934866

23. Schipper LF, Brand A, Reniers N, et al. Differential maturation of megakaryocyte progenitor cells from cord blood and mobilized peripheral blood. Exp Hematol 2003;31:324-330. PMID: 12691920

24. Zweegman S, Veenhof MA, Huijgens PC, et al. Regulation of megakaryocytopoiesis in an in vitro stroma vivo. Exp Hematol;2000 Apr;28(4):401-10. PMID: 10781898

25. Phillips DR, Charo IF, Parise LV, et al. The platelet membrane glycoprotein IIb-IIIa complex. Blood 1988;71:831-843. PMID: 2833328

26. Kanai K, Sawai S, Sogawa K, et al. Markedly upregulated serum interleukin-12 as a novel biomarker in POEMS syndrome. Neurology 2012;79:575-582. PMID: 22843279

27. Huang P, Qi Y, Xu YS, et al. Serum cytokine alteration is associated with optic neuropathy in human primary open angle glaucoma. J Glaucoma 2010;19:324-330. PMID: 19730118

28. Takatsu K. Interleukin 5 and B cell differentiation. Cytokine Growth Factor Reviews 1998;9:25-35. PMID: 9720754

29. Hirakata Y, Furuya N, Matsumoto T, et al. Influence of various immunosuppressive agents on the occurrence of endogenous bacteraemia in mice. J Med Microbiol 1995;42:181-185. PMID: 7533840

30. Kouchi Y, Maeda Y, Ohuchida A, et al. Immunotoxic effect of low dose cisplatin in mice. J Toxicol Sci 1996;21:227-233. PMID: 8959646 